\title{
Norwegian Scabies: A Challenging Dermatologic Condition
}

\author{
Massimo Federico and Larry Mellick*
}

Emergency Medicine, Medical College of Georgia, Augusta, 1120 15th Street, Georgia, 30912, USA

\begin{abstract}
Norwegian scabies is a rare skin infestation by the mite Sarcoptes scabei var hominis. This condition typically presents with widespread, crusted lesions associated with hyperkeratotic scales. The elderly, the debilitated, and patients who are immunocompromised are at risk for this more severe form of scabies. The authors discuss the presentation, diagnosis, treatment and prevention of this dermatologic condition.
\end{abstract}

Keywords: Norwegian scabies, Sarcoptes scabei var hominis, Scabies, Dermatology.

\section{INTRODUCTION}

Norwegian scabies is a rare skin infestation by the mite Sarcoptes scabei var hominis. This condition typically presents with widespread, crusted lesions associated with hyperkeratotic scales. The elderly, the debilitated, and patients who are immunocompromised are at risk for this more severe form of scabies. As with many dermatologic conditions, the diagnosis can be challenging. This article is intended to provide a broad overview of this rare skin infestation to the emergency physician or primary care provider. Awareness, recognition, confirmation of diagnosis, initiation of rapid treatment and preventive measures may help to reduce widespread infestations in susceptible populations.

\section{CASE}

A 64-year-old male was sent to the emergency department by the nursing home for evaluation of a rash and suspected severe onychomycosis. His past medical history was significant for hypertension, coronary artery disease, a cerebrovascular accident, vascular dementia, and presumed psoriasis with arthritis. Among other medications he was being treated with methotrexate.

His vital signs included temperature $36.6 \mathrm{C}$, blood pressure $110 / 72$, heart rate 130 , respirations 20 , and oxygen saturation of $98 \%$ on room air. The physical examination was remarkable for a baseline right-sided paralysis and what appeared to be a severe onychomycosis of the hands and feet, with crusting of the soles and palms, and crusting pustular lesions on the extremities. (See Figs. 1 and 2).

Following the initial evaluation in the emergency department, the patient was transferred to the dermatology clinic for consultation. Skin scrapings taken during the dermatology evaluation demonstrated mites, eggs, and scybala (mite feces). The patient was diagnosed with Norwegian or crusted scabies. Prior to being discharged back to the nursing home, treatment was initiated with topical permethrin and ivermectin oral tablets.

*Address correspondence to this author at the Pediatrics and Emergency Medicine, Medical College of Georgia, Augusta, 1120 15th Street, Georgia, 30912, USA; Tel: (706)-533-2931; Fax: (706)-364-2611;

E-mail:1mellick@mcg.edu

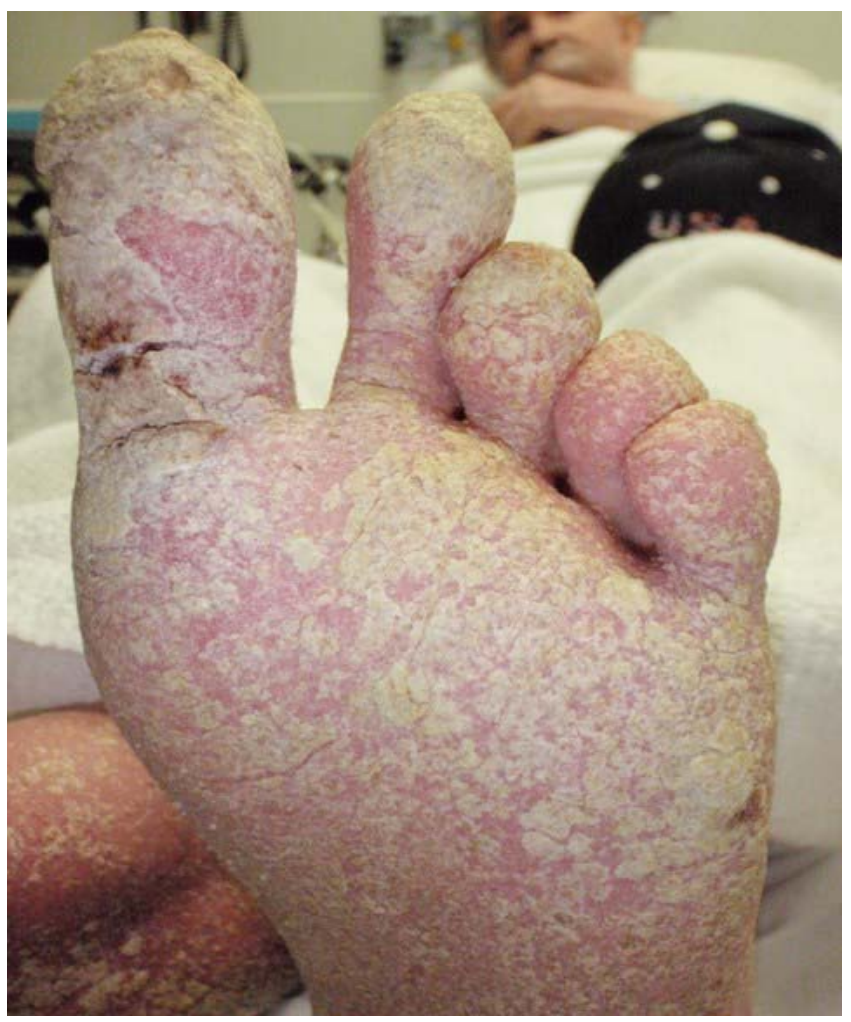

Fig. (1). Norwegian scabies in a handicapped, elderly nursing home patient.

\section{DISCUSSION}

This patient presented with a rare presentation of scabies, Norwegian scabies. Norwegian scabies is a skin infestation by the mite Sarcoptes scabei var hominis. First described in Norway in 1848 , this condition typically presents with widespread, crusted lesions associated with hyperkeratotic scales, favoring an acral distribution (elbows, knees, palms, and soles) [1]. The elderly, the debilitated, and patients who are immunocompromised are at risk for this more severe form of scabies. The same mite that causes the more common presentation of the scabies skin infestation is present in Norwe- 
gian scabies, however, the host's decreased immune response is likely responsible for the more aggressive presentation. The lack of pruritus and itching may be indicative of the absence of appropriate immune response [2, 3].

As this patient population often does not experience the urge to scratch their own skin, their lack of symptoms in the initial infestation can result in a failure to diagnose until the crusted appearance is evident [4]. In the typical case of a scabies infection, the number of mites is few in number (typically fewer than 10-15 mites on the entire body). Individuals with Norwegian or crusted scabies, however, are infected with thousands to millions of mites, and are consequently highly infectious [1]. Due to the high infectivity and potential absence of pruritus, it is advisable that residents, staff, and frequent visitors during an outbreak of scabies in a nursing home or other facility be treated even if they are not symptomatic [4].

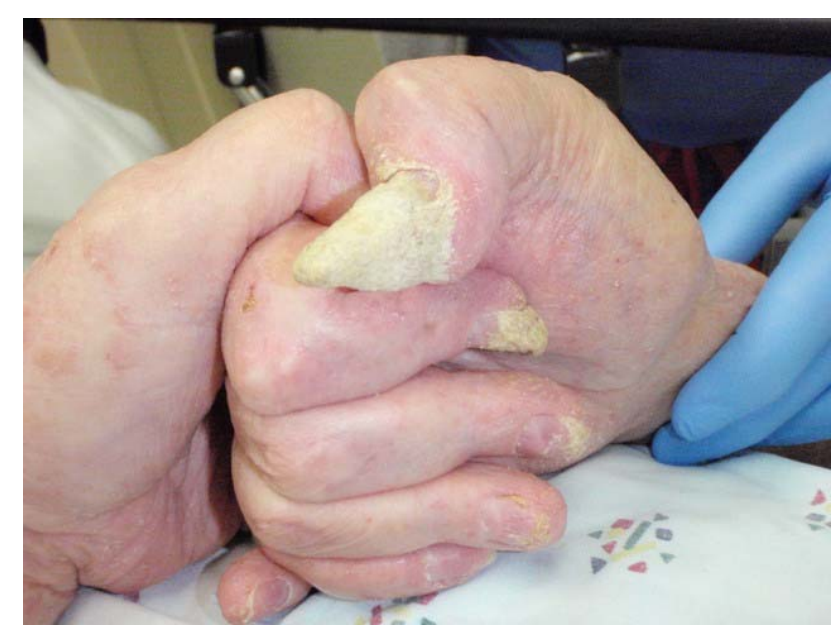

Fig. (2). Crusting, hyperkeratotic nails seen as part the Norwegian scabies presentation.

In addition to the crusting skin lesions, hyperkeratotic or dystrophic nails with large, psoriatic-like accumulations of scales under the nails are characteristic of this presentation. (Fig. 2) The dystrophic nails may persist after the hyperkeratotic lesions on the skin have been treated successfully. Mites often survive in the subungual material, increasing the potential for reinfestation. Microscopic examination of material scraped from the lesion (and from beneath the nails), using mineral oil and not $\mathrm{KOH}$, confirms the diagnosis. A hand-held magnification device can be utilized for identification of the mites, eggs or scybala [5,6]. Additionally, dermatologists may use skin biopsy, DNA PCR and ELISA, and elevated $\operatorname{IgE}$ and eosinophilia to confirm or support the diagnosis. Regardless of visual or laboratory findings, diagnosis and treatment should be based on clinical suspicion given the low risk of treatment and high potential for outbreak [7].

Successful treatment requires both topical (permethrins) and systemic (ivermectin) therapy. Close follow up in one to two week intervals is required, with repeated doses of ivermectin $(200 \mu \mathrm{g} / \mathrm{kg})$ at the same intervals given with topical scabicides (full body application), repeated initially every few days $[1,3,8]$. Crust and scale removal with keratolytics (5-10\% salicylic acid in petrolatum) is critical in Norwegian scabies to permit penetration of the topical medications [9]. Clothing, towels, and bedding should be changed and washed [10]. It is advisable to restrict, where possible, the number of staff members who care for scabies patients, whether of the Norwegian variety or otherwise, to limit the spread of the scabies [4].

\section{CONCLUSION}

Norwegian scabies is a severe and rare skin infestation that typically affects the elderly, the debilitated, and patients who are immunocompromised. Diagnosis can be made primarily by microscopy in addition to other supporting data. Treatment requires both topical and systemic therapy, along with crust and scale removal. Recognition and treatment may help to reduce widespread infestations in susceptible populations.

\section{REFERENCES}

[1] Hengge UR, Currie BJ, Jager G, et al. Scabies: a ubiquitous neglected skin disease. Lancet Infect Dis 2006; 6(12): 769-79.

[2] Hogan MT. Cutaneous Infections Associated with HIV/AIDS Dermatol Clin 2006; 24: 473-95.

[3] Howe TH, Mushtaq A, Robinson SB, Rosher RB, Khardori N. Infection in the Elderly. Infect Dis Clin N Am 2007; 21: 711-43.

[4] Scheinfeld N. Controlling scabies in institutional settings: a review of medications, treatment models, and implementation. Am J Clin Dermatol 2004; 5(1): 31-7.

[5] http: //dermatology.cdlib.org/91/abstracts/nail/17C.html

[6] Neynaber S, Wolff H. Diagnosis of scabies with dermoscopy. CMAJ 2008; 178(12): 1540-1.

[7] Chosidow O. Clinical practices. Scabies. N Engl J Med 2006; 354(16): 1718-27.

[8] Cydulka RK, Hancock M. Dermatologic presentations. In: Marx JA, Hockberger RS, Walls RM, Eds. Rosen's Emergency Medicine Concepts and Clinical Practice. $6^{\text {th }}$ ed. Philadelphia, PA: Elsevier's Health Sciences 2005; Vol 2: pp. 1854-1855/118.

[9] Karthikeyan K. Treatment of scabies: newer perspectives. Postgrad Med J 2005; 81(951): 7-11.

[10] Scabies fact sheet. Atlanta. Centers for Disease Control and Prevention. 2005 